\title{
Estimating extra length of stay and risk factors of mortality attributable to healthcare-associated infection at a Chinese university hospital: a multi-state model
}

\author{
Qian Zhou', Lili Fan', Xiaoquan Lai ${ }^{2}$, Li Tan $^{2}$ and Xinping Zhang ${ }^{1 *}$ (ID
}

\begin{abstract}
Background: The current evidence of extra length of stay (LOS) attributable to healthcare-associated infection (HCAl) scarcely takes time-dependent bias into consideration. Plus, limited evidences were from developing countries. We aim to estimate the extra LOS and risk factors of mortality attributable to HCAl for inpatients.

Methods: Multi-state model (MSM) was adopted to estimate the extra LOS attributable to HCAl of each type and subgroup. COX regression model was used to examine the risk of mortality.

Results: A total of 51,691 inpatients were included and 1709 (3.31\%) among them developed HCAI. Lower respiratory tract infection and Acinetobacter baumannii were the most prevalent HCAl and causative pathogen in surveyed institute. Generally, the expected extra LOS attributable to HCAI was 2.56 days (95\% confidence interval: 2.54-2.61). Patients below 65 had extra LOS attributable to HCAl longer about 2 days than those above. The extra LOS attributable to HCAI of male patients was 1.33 days longer than female. Meanwhile, age above 65 years old and HCAI were the risk factors of mortality for inpatients.

Conclusions: HCAl contributes to an increase in extra LOS of inpatients in China. The effect of HCAl on extra LOS is different among subgroups, with the age below 65, male and medicine department more sensitive.
\end{abstract}

Keywords: Length of stay, Multi-state model, Health-care associated infection, Mortality, Developing country

\section{Background}

Healthcare-associated infection (HCAI) is the infection acquired during the hospitalization in a patient which was not present or incubating before admission [1]. HCAI is an important public health issue due to their association with increasing prevalence, mortality and morbidity, extra length of stay (LOS) and excess cost of care. It was claimed that HCAI was the most frequent adverse event threatening the safety of patients worldwide [2]. The prevalence varied between 3.5 and $12 \%$ [3], with approximately 2 million HCAI occurring annually in the US [4]. Roberts, et al. [5] even found that HCAI would double

\footnotetext{
* Correspondence: xpzhang602@hust.edu.cn

${ }^{1}$ School of Medicine and Health Management, Tongji Medical College, Huazhong University of Science and Technology, Wuhan City, Hubei Province, People's Republic of China

Full list of author information is available at the end of the article
}

mortality and induce increase of health care costs, with hospitals losing \$7453-15,155 or even double for each patient due to HCAI, among which half of the excess cost was associated with prolonged hospitalization [5-7].

The accurate estimation of extra LOS attributable to HCAI is crucial for policy decision making, because the extra LOS is the key driver of increasing cost [8]. Most research investigated LOS attributable to HCAI using timefixed method like group comparison, matching and regression [9]. However, these estimates related to LOS attributable to HCAI own methodological limitations that neglecting time-dependent bias may result in overestimation of the extra LOS [10]. The accurate estimation needs to consider the competing risks of death, increased LOS for time-dependent bias and so on [11]. Manoukian [12] found that multi-state model (MSM) has been recommended as a technique to avoid time-dependent bias, as 
the model treats the occurrence of HCAI as timedependent covariate. Thus, the researches using MSM can provide higher quality evidence compared with other researches using time-fixed method [12].

In addition, the estimate evidence of extra LOS attributable to HCAI was limited in developing countries. Especially, there was a paucity of the relevant study controlling for time-dependence in middle-income countries [2]. In this study, we applied multi-state modeling to estimate the extra LOS attributed to HCAI of each type and subgroup so as to provide evidence of high quality in China.

\section{Methods}

\section{Setting}

The study was conducted in a teaching tertiary hospital in central China, which is on the forefront of clinical practice, scientific research and medical education in China.

\section{Participants and diagnostic criteria}

There were 51,691 patients, free of community acquired infection and hospitalized for at least $48 \mathrm{~h}$ in 35 clinical departments in 2017. The HCAI diagnostic criteria used in this work were issued by National Health Commission in China 2001 [13]. HCAI refers to infection acquired after $48 \mathrm{~h}$ of admission, unless there is a clear incubation period for the infection before $48 \mathrm{~h}$. And HCAI was diagnosed based on laboratory data, image examinations, clinical symptoms and so on, according to the diagnostic criteria. In our study, the patients hospitalized less than $48 \mathrm{~h}$ and getting community acquired infection were excluded [14].

\section{Statistical analysis}

We compared the characteristics between patients with HCAI or not, by the Manne-Whitney U-test and Chisquared test [7]. Mantel-Haenszel methods were also used to calculate unadjusted odds ratios and 95\% confidence intervals [14].

We conducted MSM to estimate extra LOS attributable to HCAI. As LOS attributable to HCAI is mainly caused by the days after HCAI acquired actually, it is necessary to account for the time of HCAI during estimation [11, 15]. Based on the pathway of patients' states during hospitalization, MSM provides a weighted average of the LOS [16]. In the 4-state model, we treated admission without infection as state 0 , HCAI acquisition as state 1 , discharge as state 2, and in-hospital death as state 3 (Fig. 1). Transitions between states were determined by timevarying hazards, which were estimated using the AaleneJohansen estimator [17]. As for patients who got more than one infection during hospitalization, we only estimated the first infection in MSM [15].

We assessed the related individual and departmental factors on the estimates of extra LOS by subgroup [18], including types of HCAI and patient characteristics such

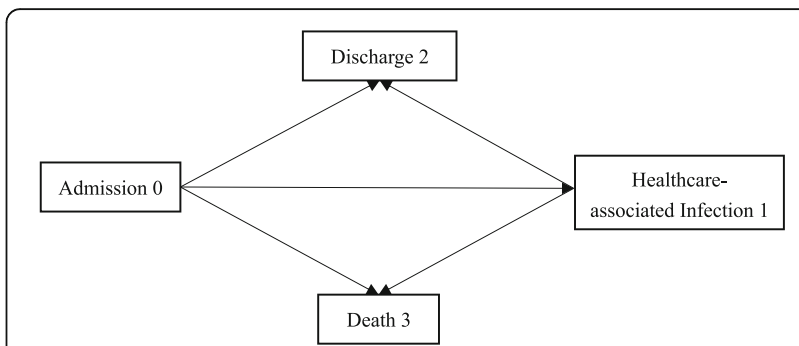

Fig. 1 Multi-state model used to determine length of stay

as age, gender and department. Those factors were investigated to have significant influence on LOS and the risk of acquiring HCAI $[19,20]$. When we estimated the extra LOS attributable to a specific type of HCAI such as bloodstream infection, we excluded surgical site infection, lower respiratory tract infection and other types. As we calculated the extra LOS attributable to HCAI varying patient characteristics such as female, we only included the female patients belonging to the needed scope. Crude extra LOS was calculated by the mean of LOS without HCAI subtracted the mean of LOS with HCAI.

Descriptive data analysis was performed using IBM SPSS Version 20.0 (IBM, New York, NY, USA). MSM analyses were performed using $\mathrm{R}$ (Team R Development Core: http://cran.r-project.org/). The variance and confidence intervals in the extra LOS were estimated using 1000 bootstrap resamples.

To examine the risk of reaching those states, we used a COX regression model adjusted for related factors, with LOS as the time variable to avoid time-dependent bias. HCAI was also included in the model as a possible predictor of death or discharge. Schoenfeld residuals were used to test the proportional risk assumption [21].

\section{Results}

Characteristics of participants and reported causative pathogens on the major types of $\mathrm{HCAl}$

Among 51,691 patients, 1709 cases of HCAI (3.31\%) experienced 1914 episodes of infection (1.12 per person). Percentage of each type of HCAI patients among admissions was presented as follows: lower respiratory tract infections (968; 50.57\%), bloodstream infection $(278 ; 14.52 \%)$, urinary tract infections $(239 ; 12.49 \%)$, upper respiratory tract infections $(71 ; 3.71 \%)$, surgical site infections $(56 ; 2.93 \%)$, skin, soft tissue (48; $2.51 \%)$.

Table 1 summarizes the characteristics of patients with and without HCAI and their comparison. Males were significantly more likely to acquire HCAI compared to females (unadjusted OR: 1.1; 95\% CI: 1.00-1.23). Patients older than 65 were significantly at risk of HCAI compared to those younger (unadjusted OR: 1.56; $95 \%$ CI: 1.40-1.73). Those who had HCAI were also more likely to die in the hospital than those without HCAI 
Table 1 Characteristics of patients with and without HCAI (n, \%)

\begin{tabular}{|c|c|c|c|c|}
\hline Characteristic & $\begin{array}{l}\text { HCAl } \\
(N=1709)\end{array}$ & $\begin{array}{l}\text { No HCAl } \\
(N=49,982)\end{array}$ & $\begin{array}{l}\text { Total } \\
(N=51,691)\end{array}$ & $P$-value \\
\hline \multicolumn{5}{|l|}{ Gender } \\
\hline Female (n, \%) & $616(36.04 \%)$ & $19,271(38.56 \%)$ & $19,887(38.47 \%)$ & \multirow[t]{2}{*}{0.036} \\
\hline Male & $1093(63.96 \%)$ & $30,711(61.44 \%)$ & $31,804(61.53 \%)$ & \\
\hline \multicolumn{5}{|l|}{ Age } \\
\hline Mean $(n, S D)$ & $54.1(19.95)$ & $50.64(18.36)$ & $50.76(18.42)$ & $<0.001$ \\
\hline$<65$ & $1201(70.28 \%)$ & $39,299(78.63 \%)$ & $40,500(78.35 \%)$ & \multirow[t]{2}{*}{$<0.001$} \\
\hline$>=65$ & $508(29.72 \%)$ & $10,683(21.37 \%)$ & $11,191(21.65 \%)$ & \\
\hline \multicolumn{5}{|l|}{ Department } \\
\hline Medicine & $297(17.38 \%)$ & $11,848(23.70 \%)$ & $12,145(23.50 \%)$ & \multirow[t]{6}{*}{$<0.001$} \\
\hline Surgical & 700 (40.96\%) & $27,022(54.06 \%)$ & $27,722(53.63 \%)$ & \\
\hline ICU & 386 (22.59\%) & $1808(3.62 \%)$ & $2194(4.24 \%)$ & \\
\hline Pediatric & $96(5.62 \%)$ & $1471(2.94 \%)$ & $1567(3.03 \%)$ & \\
\hline Psychiatric & $157(9.19 \%)$ & $6256(12.52 \%)$ & $6413(12.41 \%)$ & \\
\hline Chinese traditional medicine & $73(4.27 \%)$ & $1577(3.16 \%)$ & $1650(3.19 \%)$ & \\
\hline \multicolumn{5}{|l|}{ LOS } \\
\hline Mean (SD) & $28.71(23.501)$ & $13.90(12.418)$ & $14.51(13.201)$ & $<0.001$ \\
\hline \multicolumn{5}{|l|}{ Discharge outcome } \\
\hline Discharge alive & $1614(94.44 \%)$ & $49,614(99.26 \%)$ & $51,228(99.10 \%)$ & \multirow[t]{2}{*}{$<0.001$} \\
\hline Inpatient mortality & 95 (5.56\%) & $368(0.74 \%)$ & $463(0.90 \%)$ & \\
\hline
\end{tabular}

(unadjusted OR: 7.94; 95\% CI: 6.30-10.00). Meanwhile, HCAI showed varied incidence in different departments. Patients acquired HCAI were prone to be older and have longer LOS compared with those not.

Table 2 represents reported causative pathogens, sorted by the major 4 types of infection. One or more pathogens were reported for 901 infections. No pathogens were reported for the 1013 infections, which were diagnosed by physical symptoms and radiography and so on. Acinetobacter baumannii, Klebsiella pneumoniae, Staphylococcus aureus were the most prevalent pathogens resulted in $30.72 \%$ of all the HCAI. Acinetobacter baumannii, Klebsiella pneumoniae, Enterococcus species, Staphylococcus aureus caused most lower respiratory tract infection (LRTI), bloodstream infection (BSI), urinary tract infection (UTI), surgical site infection (SSI), respectively.

\section{Length of stay}

LOS mean comparisons and estimates from MSM are shown in Table 3. It indicated that the crude extra LOS attributable to HCAI was 14.72 days. Meanwhile according to MSM, the expected LOS due to HCAI was 2.56 days (95\% CI: 2.54-2.61) based on a standard error of 0.42 . SSI had the largest impact on the hospitalized patients, whose extra LOS was longer than other sites of HCAI, with extra LOS 14.88 days (95\% CI: 14.57-15.19). In contrast, UTI added the less extra LOS among the four types, with extra LOS 0.34 days (95\% CI: 0.29-0.42).
As the most prevalent HCAI in China, the extra LOS attributable to LRTI was a little higher than average level, with extra LOS 2.66 days (95\% CI: 2.65-2.73).

Table 4 illustrates the average LOS estimated by patient subgroup. The extra LOS was significantly decreasing with the older age. For patients aged $<65$, the extra LOS was 3.07 days (95\% CI: 3.07-3.16), while it was 1.10 days (95\% CI: 1.03-1.14) for those $>65$. When acquired with HCAI, male patients with extra LOS 3.07 days (95\% CI: $2.97-$ 3.08) were prone to be hospitalized longer than female patients with extra LOS 1.74 days (95\% CI: $1.71-1.84)$. Variability in estimates of extra LOS was noted among five clinical departments. Among them, patients in surgical department who acquired HCAI were hospitalized longer than those not, with extra LOS 5.44 days (95\%CI: 5.435.56). Patients in psychiatric department had lowest extra LOS of 1.27 days (95\%CI: 1.23, 1.29). Meanwhile, patients acquiring HCAI in pediatric, medicine and Chinese traditional medicine department had 3.80 days (95\%CI: 3.77, 3.87), 4.49 days (95\%CI: 4.15, 4.54), 2.64 days (95\%CI: 2.56 , 2.78) extra LOS compared those not, respectively.

\section{Risk of HCAl, discharge and death}

In 2017, 463 patients died in the surveyed institute. 95 (25.52\%) were infected. The most type of infected patients who died in hospital were LRTI with 51 (11.02\%) death and BSI with 25 (5.40\%) death. HCAI were 7.94 $(\mathrm{ie},=(95 / 368) /(1614 / 49614))$ times more likely to die in 
Table 2 Reported causative pathogens on the major types of HCAI (n, \%)

\begin{tabular}{|c|c|c|c|c|c|}
\hline Pathogen & $\begin{array}{l}\text { All HCAl } \\
(N=1914)\end{array}$ & $\begin{array}{l}\text { LRTI } \\
(N=968)\end{array}$ & $\begin{array}{l}\text { BSI } \\
(N=278)\end{array}$ & $\begin{array}{l}\text { UTI } \\
(N=239)\end{array}$ & $\begin{array}{l}\text { SSI } \\
(N=56)\end{array}$ \\
\hline Acinetobacter baumannii & $242(12.64)$ & $180(18.60)$ & $23(8.27)$ & $6(2.51)$ & $3(5.36)$ \\
\hline Klebsiella pneumoniae & $180(9.40)$ & $82(8.47)$ & $51(18.35)$ & $20(8.37)$ & $3(5.36)$ \\
\hline Staphylococcus aureus & $166(8.67)$ & $92(9.50)$ & $48(17.27)$ & 0 & $10(17.86)$ \\
\hline Canidia Albicans & $142(7.42)$ & 85 (8.78) & $9(3.24)$ & $36(15.06)$ & $1(1.79)$ \\
\hline Enterococcus species & $87(4.55)$ & $5(0.52)$ & $21(7.55)$ & $42(17.57)$ & $2(3.57)$ \\
\hline Pseudomonas aeruginosa & $82(4.28)$ & $54(5.58)$ & $5(1.80)$ & $7(2.93)$ & $1(1.79)$ \\
\hline Escherichia coli & $65(3.40)$ & $12(1.24)$ & $18(6.47)$ & $27(11.30)$ & $1(1.79)$ \\
\hline Candida spp. & $55(2.87)$ & $22(4.34)$ & $6(2.52)$ & $21(20.92)$ & 0 \\
\hline C.tropical & $52(2.72)$ & $20(2.07)$ & $1(0.36)$ & $29(12.13)$ & 0 \\
\hline Aspergillus spp. & $33(1.72)$ & $30(3.10)$ & $1(0.36)$ & 0 & 0 \\
\hline Coagulase-negative Staphylococcus spp. & $25(1.31)$ & $6(0.62)$ & $15(5.40)$ & 0 & $1(1.79)$ \\
\hline Neisseria & $19(0.99)$ & $1(0.10)$ & 0 & 0 & 0 \\
\hline Streptococcus viridans & $17(0.89)$ & 0 & $2(0.72)$ & 0 & 0 \\
\hline Saccharomyces & $17(0.89)$ & $6(0.62)$ & 0 & $10(4.18)$ & 0 \\
\hline Stenotrophomonas maltophilia & $16(0.84)$ & $12(1.24)$ & $2(0.72)$ & $1(0.42)$ & 0 \\
\hline Enterobacter Hormaeche and Edwards & $14(0.73)$ & $6(0.62)$ & $5(1.80)$ & 0 & 0 \\
\hline Bacillus proteus & $8(0.42)$ & $2(0.21)$ & 0 & $3(1.26)$ & 0 \\
\hline Serratia spp. & $8(0.42)$ & $5(0.52)$ & $1(0.36)$ & 0 & $2(3.57)$ \\
\hline Acinetobacter sp & $8(0.42)$ & $3(0.31)$ & $1(0.36)$ & 0 & 0 \\
\hline
\end{tabular}

$H C A I$ healthcare-associated infection, $L R T I$ lower respiratory tract infection, BSI bloodstream infection, UTI urinary tract infection, SSI surgical site infection

the hospital than those without HCAI. Namely, 694\% more patients acquired HCAI would die compared to those not (calculated in Characteristics of participants and reported causative pathogens on the major types of HCAI section), when not adjusting time-dependent factors. Patients acquired HCAI were 0.13 (ie, = (1614/ 49614)/ (95/368)) times less likely to discharge. Table 5 presents results using a Cox regression model. It was turned out that patients above 65 years old were more likely to acquire HCAI (HR: 1.383; 95\%CI: 1.246, 1.534). Besides patients above 65 years old were more likely to die (HR: 2.704; 95\%CI: 2.250, 3.250). HCAI also significantly was the risk factor of death (HR:2.921; 95\%CI: 2.307, 3.698), considering the time-dependent biases.

Table 3 Estimates of extra LOS attributable to the types of HCAI

\begin{tabular}{lllll}
\hline & Crude extra LOS $^{\text {a }}$ & MSM extra LOS & SE & $95 \% \mathrm{Cl}$ \\
\hline HCAI & 14.72 & 2.56 & 0.42 & $(2.54,2.61)$ \\
BSI & 17.21 & 3.92 & 1.60 & $(3.90,4.18)$ \\
UTI & 13.63 & 0.34 & 0.75 & $(0.29,0.42)$ \\
SSI & 32.68 & 14.88 & 3.49 & $(14.57,15.19)$ \\
LRTI & 13.09 & 2.66 & 0.48 & $(2.65,2.73)$ \\
\hline
\end{tabular}

HCAI healthcare-associated infection, $B S I$ bloodstream infection, UTI urinary tract infection, SSI surgical site infection, $L R T I$ lower respiratory tract infection a Defined as the difference in mean LOS between patients with and without HCAl or a specific type of HCAI

\section{Discussion}

To our best knowledge, this is the first study to estimate the extra LOS attributable to HCAI applying multi-state model in developing countries as well as the risk of HCAI, discharge and death. Considering the main limitations of MSM model that it is difficult to account for other baseline covariates in analysis, we estimate extra LOS by conducting subgroup analysis to understand extra LOS attributable to HCAI clearly.

The distribution of prevalent HCAI in our study is consistent with the previous prevalence from 52 Chinese hospitals and from a teaching hospital [22, 23], where lower respiratory tract infection was the most prevalent HCAI. We also got the similar results of documented HCAI ratio and mortality compared to previous study $[24,25]$. As for causative pathogens, we found that Acinetobacter baumannii was most prevalent. In fact, the percentage of Acinetobacter baumannii is high among pathogens causing HCAI in China compared to other countries [26]. On the contrary, Clostridium difficile, frequently reported pathogen in the USA, was not reported in this study. That might be owing to samples' low submission rate and poor diagnosis in China, which was the same condition in the surveyed institute $[27,28]$.

The extra LOS attributable to HCAI was 2.56 days in this study. The result is quite similar to the research conducted in Australia using regression model to estimate the 
Table 4 Estimates of extra LOS attributable to HCAl of subgroups

\begin{tabular}{|c|c|c|c|c|}
\hline & $\begin{array}{l}\text { Crude } \\
\text { extra LOS }\end{array}$ & $\begin{array}{l}\text { MSM } \\
\text { extra LOS }\end{array}$ & SE & $95 \% \mathrm{Cl}$ \\
\hline \multicolumn{5}{|l|}{ Patient characteristics } \\
\hline \multicolumn{5}{|l|}{ Age } \\
\hline$<65 y$ & 14.86 & 3.07 & 0.53 & $(3.06,3.16)$ \\
\hline $65+y$ & 16.00 & 1.10 & 0.62 & $(1.03,1.14)$ \\
\hline \multicolumn{5}{|l|}{ Gender } \\
\hline Female & 12.01 & 1.74 & 0.77 & $(1.71,1.84)$ \\
\hline Male & 16.22 & 3.07 & 0.56 & $(2.97,3.08)$ \\
\hline \multicolumn{5}{|l|}{ Department } \\
\hline Medicine & 16.72 & 4.49 & 1.00 & $(4.15,4.54)$ \\
\hline Surgical & 19.34 & 5.44 & 0.73 & $(5.43,5.56)$ \\
\hline Pediatric & 11.42 & 3.80 & 1.18 & $(3.77,3.87)$ \\
\hline Psychiatric & 6.95 & 1.27 & 0.51 & $(1.23,1.29)$ \\
\hline $\begin{array}{l}\text { Chinese traditional } \\
\text { medicine }\end{array}$ & 14.78 & 2.64 & 1.79 & $(2.56,2.78)$ \\
\hline
\end{tabular}

${ }^{a}$ Defined as the difference in mean LOS between patients with and without HAls

extra LOS [29]. Compared to the previous studies conducted by the case-compared method in China, the estimates are shorter $[30,31]$. The reason might be overestimation of LOS time-dependent bias in most researches. As for studies using MSM in other developed countries, they found that the extra LOS attributable to HCAI ranging from 0.9 to 11.5 days $[6,18]$. Some of them is consistent with our study. Different from previous findings that older patients tended to be hospitalized longer than those younger [23], the extra LOS attributable to HCAI for those aged less than 65 is longer than those above 65 when considered time-dependent bias in our study. Some researchers draw the same conclusion as we did $[18,32]$. It might be explained by the less relative impact of HCAI on older patients than those younger [32].

Table 5 Risk of HCAl and death using a Cox regression model

\begin{tabular}{lllll}
\hline Outcome & Predictor & HR & $95 \% \mathrm{Cl}$ & -value \\
\hline HCAl & Age & & & \\
& Below 65 years old & 1 & & \\
& Above 65 years old & 1.383 & $(1.246,1.534)$ & $<0.001$ \\
DEAD & Age & & & \\
& Below 65 years old & 1 & & \\
& Above 65 years old & 2.704 & $(2.250,3.250)$ & $<0.001$ \\
& HCAl & & & \\
& Not acquire HCAl & 1 & & \\
Acquire HCAl & 2.921 & $(2.307,3.698)$ & $<0.001$
\end{tabular}

Schoenfeld residuals

HCAl as outcome: test: Age: $p=0.837$

DEAD as outcome: Global test: $p=0.552$; detailed test: Age: $p=0.295$; HCAl: $p=0.707$
In addition, we found male patients had longer extra LOS attributable to HCAI than female patients. Consistent with the extra LOS estimates in German, male patients were hospitalized longer than female [18]. The reason might be that men were at higher risk of BSI and SSI, which was probably due to skin or other anatomical differences [23]. It was suggested that thicker, coarser hair of male contributed to higher BSI and SSI [33]. Meanwhile, we found that BSI and SSI exactly turned out to prolong LOS longer in our study, which was also approved by Angelis GD [34].

The work reveals implications for healthcare researchers and medical staff. We provided a precise estimate of extra LOS attributable to HCAI based on MSM avoiding timedependent bias. Besides, the accurate estimates improve awareness of medical staff on prevention of HCAI. And a wide range of infection rates can reduce by preventive measures [35]. Thus, medical staff should pay more attention to implementing infection prevention measures.

There are limitations in our study. Its findings may not generalize to other settings based on one hospital survey in China. While lots of ICU patients in investigated hospital were often treated both in ICU and general units without clear pathway, so we could not specify them associated with LOS. Hence, we didn't estimate the extra LOS for patients in ICU [6]. Meanwhile, disease severity such as comorbidity and entering ICU or not was not controlled in the model. The community acquired infection might be potentially omitted.

Future studies would explore a model on estimating excess LOS attributable to HCAI on account of more than one HCAI. The effect of infection with documented microbiological result and not on LOS would also be considered.

\section{Conclusions}

HCAI is attributable to an increase in extra LOS of patient hospitalization, considering the time-dependent bias, as well as the variation including patient age, department and type of infections. The results estimated in our study using MSM help improve the accuracy in estimation of burden of HCAI in the future. Older age and HCAI are risk factors of patient mortality. The interventions to prevent infection during patient hospitalization are required.

\section{Abbreviations}

BSI: Bloodstream infection; HCAl: Healthcare-associated infection; LOS: Length of stay; LRTI: Lower respiratory tract infection; SSI: Surgical site infection; UTI: Urinary tract infection

\section{Acknowledgements}

The authors would like to thank Yanfang Liang, Qian Lv and all stuffs in Department of Nosocomial Infection of Tongji Hospital for their professional suggestions on HCAl and data collection. The authors would like to thank Yuqing Tang, Chenxi Liu, Dan Wang, Haihong Chen and Junjie Liu for the manuscript writing. 


\section{Authors' contributions}

QZ conducted the study design, data collection, data analysis, and drafted the manuscript. LF and LT made significant contributions to data collection and analysis. XL and XZ provided assistance in study design and manuscript drafting. All authors read and approved the final manuscript.

\section{Funding}

This work was supported by the National Natural Science Foundation of China (No.71473098). Study sponsors were not involved in the process of manuscript drafting.

\section{Availability of data and materials}

The data used in the study was available from the Department of nosocomial department of Tongji Hospital of Huazhong University of Science and Technology. The datasets are available from administrative permissions from the chief of nosocomial department, who is one of our authors.

\section{Ethics approval and consent to participate}

The study was deemed exempt from review by the Ethics Committee of Tongji Medical College, Huazhong University of Science and Technology as routine data for clinical purpose were used and all the information of patients was kept confidential in the study. The raw data acquisition required administrative permission of the chief of nosocomial department in Tongji hospital.

\section{Consent for publication}

Not applicable.

\section{Competing interests}

The authors declare that they have no competing interests.

\section{Author details}

${ }^{1}$ School of Medicine and Health Management, Tongji Medical College, Huazhong University of Science and Technology, Wuhan City, Hubei Province, People's Republic of China. ${ }^{2}$ Department of Nosocomial Infection, Tongji Hospital, Tongji Medical College, Huazhong University of Science and Technology, Wuhan City, Hubei Province, People's Republic of China.

Received: 27 February 2019 Accepted: 13 September 2019

Published online: 20 November 2019

\section{References}

1. WHO. The burden of health care-associated infection worldwide. https:// www.who.int/gpsc/country_work/burden_hcai/en/. Accessed 1 Dec 2018.

2. Allegranzi B, Nejad SB, Combescure C, et al. Burden of endemic health-careassociated infection in developing countries: systematic review and metaanalysis. Lancet. 2011;377(9761):228-41. https://doi.org/10.1016/S01406736(10)61458-4.

3. WHO. Health care-associated infections FACT SHEET. [https://www.who.int/ gpsc/country_work/gpsc_ccisc_fact_sheet_en.pdf]. Accessed 1 Dec 2018.

4. Jarvis WR. Selected aspects of the socioeconomic impact of nosocomial infections: morbidity, mortality, cost, and prevention. Infect Control Hosp Epidemiol. 1996:17(8):552-7.

5. Roberts RR, Scott RD 2nd, Hota B, et al. Costs attributable to healthcareacquired infection in hospitalized adults and a comparison of economic methods. Med Care. 2010;48(11):1026-35.

6. Arefian H, Hagel S, Heublein S, Rissner F, Scherag A, Brunkhorst FM, et al. Extra length of stay and costs because of health care-associated infections at a German university hospital. Am J Infect Control. 2016;44(2):160-6. https://doi.org/10.1016/j.ajic.2015.09.005.

7. Nosrati M, Boroumand M, Tahmasebi S, Sotoudeh M, Sheikhfathollahi M, Goodarzynejad H. Excess costs associated with common healthcareassociated infections in an Iranian cardiac surgical unit. J Hosp Infect. 2010; 76(4):304-7. https://doi.org/10.1016/j.jhin.2010.07.003.

8. Roberts R, Scott RD 2nd, Houtz LK, et al. Costs Attributable to HealthcareAcquired Infection in Hospitalized Adults and a Comparison of Econo Methods. Med Care. 2010;48(11):1026-35.

9. Nelson RE, Nelson SD, Khader K, Perencevich EL, Schweizer ML, Rubin MA, et al. The magnitude of time-dependent bias in the estimation of excess length of stay attributable to healthcare-associated infections. Infect Control Hosp Epidemiol. 2015;36(9):1089-94. https://doi.org/10.1017/ice.2015.129.

10. Wolkewitz M, von Cube M, Schumacher M. Multistate modeling to analyze nosocomial infection data: an introduction and demonstration. Infect Control Hosp Epidemiol. 2017;38(8):953-9. https://doi.org/10.1017/ice.2017.107.

11. Beyersmann JGP, Grundmann H, et al. Use of multistate models to assess prolongation of intensive care unit stay due to nosocomial infection. Infect Control Hosp Epidemiol. 2006;27(5):493-9.

12. Manoukian S. Estimating excess length of stay due to healthcare-associated infections a systematic review and meta-analysis of statistical methodology. J Hosp Infect. 2018:222-35. https://doi.org/10.1016/j.jhin.2018.06.003.

13. National Health and Family Planning Commission of the People's Republic of China. Notice on Issuing Diagnostic Criteria for Nosocomial Infection. [http://www.moh.gov.cn/yzygj/s3593/200804/e19e4448378643a09913ccf2 a055c79d.shtml]. Accessed 1 Dec 2018.

14. Mitchell BG, Ferguson JK, Anderson M, Sear J, Barnett A. Length of stay and mortality associated with healthcare-associated urinary tract infections: a multi-state model. J Hosp Infect. 2016;93(1):92-9. https://doi.org/10.1016/j.jhin.2016.01.012.

15. Barnett AG, Page K, Campbell M, Martin E, Rashleigh-Rolls R, Halton K, et al. The increased risks of death and extra lengths of hospital and ICU stay from hospital-acquired bloodstream infections: a case-control study. BMJ Open. 2013;3(10):e003587. https://doi.org/10.1136/bmjopen-2013-003587.

16. Shaw E, Gomila A, Piriz M, Perez R, Cuquet J, Vazquez A, et al. Multistate modelling to estimate excess length of stay and risk of death associated with organ/space infection after elective colorectal surgery. J Hosp Infect. 2018;100(4):400-5. https://doi.org/10.1016/j.jhin.2018.08.010.

17. van Kleef E, Green N, Goldenberg SD, Robotham JV, Cookson B, Jit M, et al. Excess length of stay and mortality due to Clostridium difficile infection: a multi-state modelling approach. J Hosp Infect. 2014;88(4):213-7. https://doi. org/10.1016/j.jhin.2014.08.008.

18. Stevens W, Khader K, Nelson RE, Jones M, Rubin MA, Brown KA, et al. Excess length of stay attributable to Clostridium difficile infection (CDI) in the acute care setting: a multistate model. Infect Control Hosp Epidemiol. 2015; 36(9):1024-30. https://doi.org/10.1017/ice.2015.132.

19. Zhang $Y$, Zhang J, Wei $D$, et al. Annual surveys for point-prevalence of healthcare-associated infection in a tertiary hospital in Beijing, China, 20122014. BMC Infect Dis. 2016;16(1):1-7. https://doi.org/10.1186/s12879-016-1504-4.

20. Almashrafi A, Elmontsri M, Aylin P. Systematic review of factors influencing length of stay in ICU after adult cardiac surgery. BMC Infect Dis. 2016;16(1): 1-7. https://doi.org/10.1186/s12913-016-1591-3.

21. Grambsch PM, Therneau TM. Proportional hazards tests and diagnostics based on weighted residuals. Biometrika. 1994;81(3):515-26. https://doi.org/ 10.1093/biomet/81.3.515

22. Tao XB, Qian LH, Li Y, Wu Q, Ruan JJ, Cai DZ, et al. Hospital-acquired infection rate in a tertiary care teaching hospital in China: a cross-sectional survey involving 2434 inpatients. Int J Infect Dis. 2014;27:7-9. https://doi. org/10.1016/j.ijid.2014.05.011.

23. Chen $Y$, Zhao JY, Shan $X$, et al. A point-prevalence survey of healthcareassociated infection in fifty-two Chinese hospitals. J Hosp Infect. 2017;95(1): 105-11. https://doi.org/10.1016/j.jhin.2016.08.010.

24. Zarb P, Coignard B, Griskeviciene J, et al. The European Centre for Disease Prevention and Control (ECDC) pilot point prevalence survey of healthcareassociated infections and antimicrobial use. Euro Surveill. 2012;17(46):4-19.

25. Chang L. Factors associated with poor hospital mortality rates after the National Health Insurance program. Asia Pac J Public Health. 2015;27(2):NP903.

26. Wang J, Hu J, Harbarth S, Pittet D, Zhou M, Zingg W. Burden of healthcareassociated infections in China: results of the 2015 point prevalence survey in Dong Guan City. J Hosp Infect. 2017;96(2):132-8. https://doi.org/10.1016/j. jhin.2017.02.014.

27. Hawkey PM, Marriott C, Liu WE, Jian ZJ, Gao Q, Ling TK, et al. Molecular epidemiology of Clostridium difficile infection in a major chinese hospital: an underrecognized problem in Asia? J Clin Microbiol. 2013;51(10):3308-13. https://doi.org/10.1128/JCM.00587-13.

28. Liu JY, Wu YH, Cai M, Zhou CL. Point-prevalence survey of healthcareassociated infections in Beijing, China: a survey and analysis in 2014. J Hosp Infect. 2016;93(3):271-9. https://doi.org/10.1016/j.jhin.2016.03.019.

29. Graves N, Weinhold D, Tong E, Birrell F, Doidge S, Ramritu P, et al. Effect of healthcare-acquired infection on length of hospital stay and cost. Infect Control Hosp Epidemiol. 2007;28(3):280-92. https://doi.org/10.1086/512642.

30. Lu Y, Cai MH, Cheng J, et al. A multi-center nested case-control study on hospitalization costs and length of stay due to healthcare-associated 
infection. Antimicrob Resist Infect Control. 2018;7:99. https://doi.org/10. 1186/s13756-018-0386-1.

31. Bao-qin FJ-gC. Case-control study of influence of methicillin-resistant Staphylococcus aureus infection on economic losses and length of hospital stay. Chin J Nosocomiol. 2014;10:2363-5 (in Chinese).

32. Ohannessian R, Gustin MP, Benet T, Gerbier-Colomban S, Girard R, Argaud L, et al. Estimation of extra length of stay attributable to hospital-acquired infections in adult ICUs using a time-dependent multistate model. Crit Care Med. 2018;46(7):1093-8. https://doi.org/10.1097/CCM.0000000000003131.

33. Cohen B, Choi YJ, Hyman S, et al. Gender Differences in Risk of Bloodstream and Surgical Site Infections. J Gen Intern Med. 2013;28(10): 1318-25. https:/doi.org/10.1007/s11606-013-2421-5.

34. Angelis GD, Allignol A, Murthy A, Wolkewitz M, Beyersmann J, Safran E, et al. Multistate modelling to estimate the excess length of stay associated with meticillin-resistant Staphylococcus aureus colonisation and infection in surgical patients. J Hosp Infect. 2011;78(2):86-91. https://doi.org/10.1016/j. jhin.2011.02.003.

35. Harbarth S, Sax H, Gastmeier P. The preventable proportion of nosocomial infections an overview of published reports. J Hosp Infect. 2003;54(4):258-66. https://doi.org/10.1016/\$0195-6701(03)00150-6.

\section{Publisher's Note}

Springer Nature remains neutral with regard to jurisdictional claims in published maps and institutional affiliations.

Ready to submit your research? Choose BMC and benefit from:

- fast, convenient online submission

- thorough peer review by experienced researchers in your field

- rapid publication on acceptance

- support for research data, including large and complex data types

- gold Open Access which fosters wider collaboration and increased citations

- maximum visibility for your research: over $100 \mathrm{M}$ website views per year

At BMC, research is always in progress.

Learn more biomedcentral.com/submissions 